\title{
A decentralized/self-sustaining (infra-free) kitchen-system proposal with a home incinerator and Sabatier reactor-integrated waste management utility
}

\author{
S. Anilir \\ Department of Architecture, Graduate School of Engineering, \\ University of Tokyo, Japan
}

\begin{abstract}
This paper studies a decentralized process for solid, liquid and gas waste management in a single-person household $(\mathrm{HH})$, in which the kitchen produces less or no garbage and returns valuable products to support its own system. It particularly focuses on two $\mathrm{CO}_{2}$-consuming solid waste management scenarios; (1) to use garbage as a power source with a home incinerator to run a Sabatierreactor with an outcome of energy (methane) and water; and (2) to produce hydrogen from methane and water in order to close the lifecycle, which otherwise has to be supplied from outside. Further integration of a hydroponic unit controls the flow of excess gases to produce food, provide clean air while cooling the incinerator and improving combustion efficiency. The volume requirement of approximately $2 \mathrm{~m}^{3}$ could be integrated inside a prefabricated wall so that the waste management utility can be easily commercialized and installed without additional space requirements. Due to decentralization process and elimination of municipal waste collection, process and treatment infrastructure, installing the IF system could serve as a catalyst in the reduction of approximately 187 million tons of $\mathrm{CO}_{2}$-emission in the case of Japan; a $9 \%$ decrease from the 1990 emission values, where the target is set for $6 \%$ by 2012 . Thus, it minimizes stress to expensive landfill area; integrating the potential of solid waste into the daily lifecycle and proposing a future kitchen system for everyday and emergency use, both in developing and industrialized countries.
\end{abstract}

Keywords: infra-free, decentralization, resource utilization, hydroponics, home incinerator. 


\section{Introduction}

Municipal solid waste (garbage) refers to $\mathrm{HH}$ waste purely for living purposes and without commercial gain. They are dumped and/or brought to collection areas, which is later disposed by a city-supported social infrastructure including collection, transfer and treatment/reduction facilities through incineration, landfills, waste-to-energy facilities and land applications accompanying important financial and/or environmental issues.

The garbage in a $\mathrm{HH}$ is mostly produced or stored in kitchens. The influence of evolving information technologies reshape our kitchens with networked appliances like GE's self-restocking refrigerators connected to online grocery stores [1], computer controlled dishwashers or sensor technologies performing health checks improving comfort and assuring a safer environment for both young and elderly users. However, the wish for a better lifestyle results in adding new source-consuming appliances into $\mathrm{HH}$ and thereby, increases energy and water use, which puts more stress on our environment and centralized infrastructures. This already is a major cause of ecological decline and high lifecycle cost with utility development, maintenance, operation and replacement.

The Infra-Free (IF) research studies the concept of a decentralized lifestyle, where all type of solid and liquid waste sources produced in a $\mathrm{HH}$ are integrated for source reduction, reuse or recycling, treatment to process and reprocess waste to recover useful sources on-site [2]. It differs from other approaches in a sense that the proposed closed life-cycle system do not depend on environmental conditions like solar and wind power or rainwater; but on waste sources basically produced in every $\mathrm{HH}$, which makes it universal.

IF describes the effective management of waste management cycle as (a) reducing the amount of sources to supply one $\mathrm{HH}$, and (b) reducing the amount of waste sources leaving from a single HH. This paper will analyze likely limitations for scenario (b) with a special focus on solid waste management.

\section{Solid waste management}

IF projects an increase of approximately 2.2 million tons of solid waste in 2020 in Japan, even with the population trends set to decrease in the future, the trend of increasing single or one-couple $\mathrm{HH}$ will produce more waste than now [3]. This paper focuses on increasing single $\mathrm{HH}$, which generates $941 \mathrm{~g} /$ person/ day compared to a four-person $\mathrm{HH}$, which is $440 \mathrm{~g} /$ person/ day, in which a study on solid waste reduction could lead to a new type of decentralization.

Solid wastes could be reduced with either physicochemical or biological processes. Because biological systems require certain waste composition, more time and reactor volume, we focus only on physicochemical process technologies, as shown in Table 1.

All physicochemical technologies produce directly or indirectly $\mathrm{CO}_{2}$ as a byproduct. For an IF scenario, two important aspects would be that:

a) the selected technology is well-understood and widely used at a macroscale, should be capable to process all kinds of waste and contribute to reduction of solid waste on-site (decentralization) process 
b) the by-product $\left(\mathrm{CO}_{2}\right)$ is efficiently reduced or completely eliminated by an integrated technology which would result in source recovery for direct or indirect use at $\mathrm{HH}$

Table 1: Possible physicochemical solid waste process technologies for households.

\begin{tabular}{|c|c|c|}
\hline Technology & $\begin{array}{c}\text { Items technology } \\
\text { can process }\end{array}$ & Post-process products \\
\hline Incineration & Any kind of waste & $\begin{array}{l}\text { Ash, flue gases, heat, } \\
\mathrm{CO}_{2} \text {, water }\end{array}$ \\
\hline $\begin{array}{l}\text { Indirect } \\
\text { Electrochemical } \\
\text { Oxidation }\end{array}$ & Soluble organic materials & $\begin{array}{l}\mathrm{CO} 2 \text {, volatile organic } \\
\text { compounds, } \mathrm{Cl}_{2}, \mathrm{HCl}\end{array}$ \\
\hline Pyrolysis Process & Mixed solid waste & Solids, $\mathrm{CO}_{2}, \mathrm{H}_{2} \mathrm{O}, \mathrm{CH}_{4}$ \\
\hline Gasification & High-heat value materials & Energy, Effluent, Ash \\
\hline $\begin{array}{l}\text { Supercritical } \mathrm{H}_{2} \mathrm{O} \\
\text { (Water) Oxidation }\end{array}$ & $\begin{array}{l}\text { Puree, } \sim 10 \% \text { organic, } \sim 3 \% \\
\text { inorganic, } \sim 15 \% \text { solids }\end{array}$ & $\begin{array}{l}\text { Organic free oxides, } \\
\mathrm{CO}_{2} \text { oxides, } \mathrm{N}_{2}, \mathrm{~N}_{2} \mathrm{O}\end{array}$ \\
\hline Lyophilization & Feces and biomass & Water, dry waste \\
\hline $\begin{array}{l}\text { Hydrogen-Peroxide } \\
\left(\mathrm{H}_{2} \mathrm{O}_{2}\right) \text { Oxidation }\end{array}$ & $\begin{array}{l}\text { Paper, plastics, human } \\
\text { waste, inedible biomass }\end{array}$ & $\begin{array}{l}\mathrm{CO}_{2}, \text { ash, } \\
\text { energy from steam }\end{array}$ \\
\hline $\begin{array}{l}\text { Plasma Arc } \\
\text { Incineration }\end{array}$ & Combustibles & $\mathrm{CO}_{2}$, nitrates, $\mathrm{NO}_{\mathrm{x}}$ \\
\hline Carbon Activation & Cellulosic waste & Active Carbon, energy \\
\hline
\end{tabular}

Because of the capability in treating any kind of solid waste, we focus on 'incineration' technology to study further in a compact scale for HH. The latest material and filter technologies may enable to build home incinerators. Thereby we will try to eliminate the emission of waste ' carbon content (which is the case of both incineration facilities and even, mobile small-scale incinerators used in rural areas to reduce the amount of agricultural waste) by further study using $\mathrm{CO}_{2}$ with a Sabatier reactor in $\mathrm{HH}$ to recover sources; in form of energy or water.

\subsection{Home incinerator}

'Home incinerators' have not been studied in detail before. The main reason could be the control of off-gases, danger of using a combustor at home or convenience of solid waste treatment facilities. There is only one patent (US6422159) about the proposal of a home incinerator using a combustion vessel, a base trap and an afterburner [4], where the garbage is burned and $\mathrm{CO}_{2}$ is released into the atmosphere, similar to an incineration facility. Extracting the energy of garbage for heating and power in $\mathrm{HH}$ level could conserve commercial fuels while reducing carbon gases released into the atmosphere and saving limited landfill areas; especially for high-density cities like Tokyo.

It is essential that the house incinerator operates at elevated high temperatures; high enough to combust toxic wastes, but not too high to produce 
flue gases or flu ash- with a clean fuel required for start up and shut down. Such an incinerator would require about $200 \mathrm{~W}$ of continuous electrical power and about $600 \mathrm{~W}$ when starting up for a two-hour slow-burning process with a total energy use of about $550 \mathrm{~W}$. A low-mass compact design could improve the combustion efficiency with lower energy input. We will assume that the system will use $0.5 \mathrm{kWh} /$ day.

For most efficiency, garbage has to be dry before burning. A separate feeding gate with a rotating chamber similar to a towel drying unit could recover water from organic wastes with high water content. The rest of the dry organic waste would then be led to main combustor for incineration process. Recovered water with nutrients goes to a hydroponic plant unit located inside the kitchen, and a LED-light system adjusts the necessary amount of light waves for the planted seed. An in-out air inlet is also installed so that stale room air is redirected to the incinerator; pre-warmed before entering the unit and cooling incinerator surface.

The combustion of waste produces energy and heat; a well understood technology used in many different waste treatment facilities. In Denmark, incinerating 1 ton of waste produces approximately $2 \mathrm{MWh}$ district heating and 0.67MWh electricity [5]. Garbage contains the same mass fraction of carbon as $\mathrm{CO}_{2}$ itself, which is $27 \%$, so incineration of one kilogram of $\mathrm{HH}$ garbage will produce one kilogram of $\mathrm{CO}_{2}$. However, the excess air will not be pure enough for the Sabatier reactor, $\mathrm{CO}_{2}$ has to be separated from other gases before processing. This could be achieved with reusable membrane filters containing specialized polymers to increase $\mathrm{CO}_{2}$ solubility. At temperatures above $250^{\circ} \mathrm{C}$, conversion rates are about $90 \%$ [6]. Watanabe states the amount of garbage fuel as $85 \%$ [7]. This would result in $720 \mathrm{~g} / \mathrm{CO}_{2}$ per day for a single- $\mathrm{HH}$. The calorific value of waste is $10.5 \mathrm{MJ} / \mathrm{kg}$ on average [5]. The recovery of heat passing through a steam turbine could theoretically produce $2.1 \mathrm{kWh} /$ day.

\subsection{The sabatier reactor}

The Sabatier process is a moderately exothermic reaction, which involves the catalytic activation of $\mathrm{CO}_{2}$ in the presence of hydrogen at elevated temperatures to produce methane and water, as shown in eqn (1). It is thermodynamically stable without the power requirement to maintain its temperature.

$$
\mathrm{CO}_{2}+4 \mathrm{H}_{2}=\mathrm{CH}_{4}+2 \mathrm{H}_{2} \mathrm{O} \triangle \mathrm{H}=-165-\mathrm{kj} / \mathrm{mol} \text { (exothermic) }
$$

The reactor is not bigger than a small lightweight steel cylinder with mixing chamber and a chamber filled with nickel catalyst. The reaction is exothermic and once started, it will maintain itself at about $573^{\circ} \mathrm{K}$; however, an electrical power of $1831 \mathrm{~kJ}(0.51 \mathrm{kWh})$ would be required to break $\mathrm{H}-\mathrm{H}, \mathrm{C}$ and $\mathrm{O}-\mathrm{O}$ molecules amd start up the reaction. Fig. 1 shows the conceptual outline of a home incinerator system.

The flow of Fig.1 would have a net energy output of $1.22 \mathrm{kWh} /$ day, $0.6 \mathrm{~L}$ water and $14.5 \mathrm{MJ}$ heat. Units adding into the total weight of the kitchen are $4.85 \mathrm{~kg}$ (excluding the hydroponics unit) and require an installation space of $1.93 \mathrm{~m}^{3}$ (with the hydroponics unit). Warm stale air cools the exothermic reactor to maintain the optimum temperature and supplies excess home-air as clean fuel. 


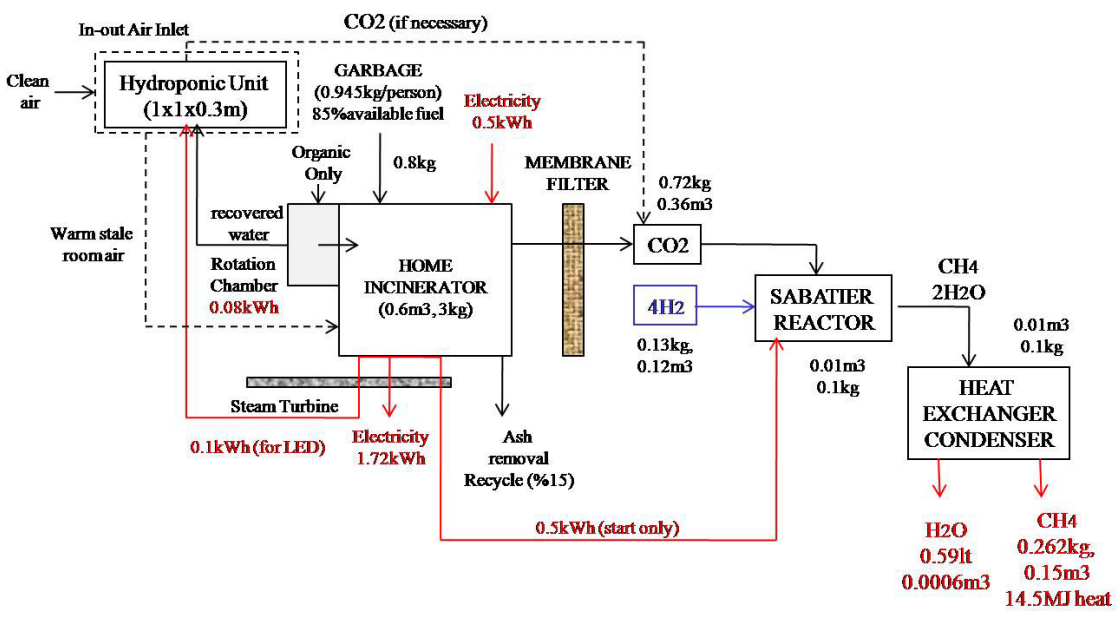

Figure 1: A Sabatier-reactor integrated home incineration unit.

\section{At-home hydrogen production scenarios}

A disadvantage of system in Fig.1 is that hydrogen must be continuously supplied. For a future hydrogen economy, this system seems applicable. However, hydrogen is not suited for transportation in tanks and storage is not easy either. Because the molecular weight of hydrogen is $2.0159 \mathrm{~g} / \mathrm{mol}$ and $\mathrm{CO}_{2}$ is $44.0098 \mathrm{~g} / \mathrm{mol}$, the reaction with $720 \mathrm{~g} \mathrm{CO}_{2}$ will need about $130 \mathrm{~g}$ of hydrogen; thus it would require $12 \mathrm{~L}$ of storage space even if hydrogen is compressed at 2,200psi. This would increase the space used for the system in the kitchen or possibly require installing tanks outside home. The following scenarios focus on two possible scenarios to semi- or completely close the hydrogen loop in order to eliminate storage tanks while analyzing system requirements and capability.

\subsection{Semi-closed hydrogen production system}

Methane and water are end-products of a Sabatier system. As an initial approach, methane could be further processed using pyrolysis, which is a heating process in an enclosed device in the absence of oxygen to recover $\mathrm{H}_{2}$ and $\mathrm{C}$; where the $\mathrm{H}_{2}$ could be redirected to the Sabatier reactor and left-over pyrolytic graphite can be removed. However, this would require far more energy than produced and would not completely recover all sources. Thus, methane already provides an important amount of heat energy right after the Sabatier process. So, IF-Kitchen will focus on reprocessing water as a source for hydrogen production.

The amount of water after Sabatier process is approximately $0.6 \mathrm{~L}$. Recovering hydrogen from water could be realized through an electrolysis process, which is well-understood, as shown in eqn (2). Although solid polymer systems have good chemical and mechanical stability, high efficiency, reduced number of moving parts and easy maintenance; we select alkaline systems to 
reduce costs by a factor of four due to the costs of membrane and catalyst materials.

$$
2 \mathrm{H}_{2} \mathrm{O}=\mathrm{O}_{2}+2 \mathrm{H}_{2} \quad \triangle \mathrm{H}=486.6 \mathrm{kj} / \mathrm{mol} \text { (endothermic) }
$$

The hydrogen end-product could be directed to Sabatier reactor reducing the amount of supplied hydrogen to half, while released oxygen could be injected inside the combustion chamber just before the scrubber to increase efficiency of incineration process (and thereby decrease necessary energy) providing clean fuel and also to complete the reaction converting $\mathrm{SO}_{2}$ to $\mathrm{CO}_{2}$, as shown in Fig.2.

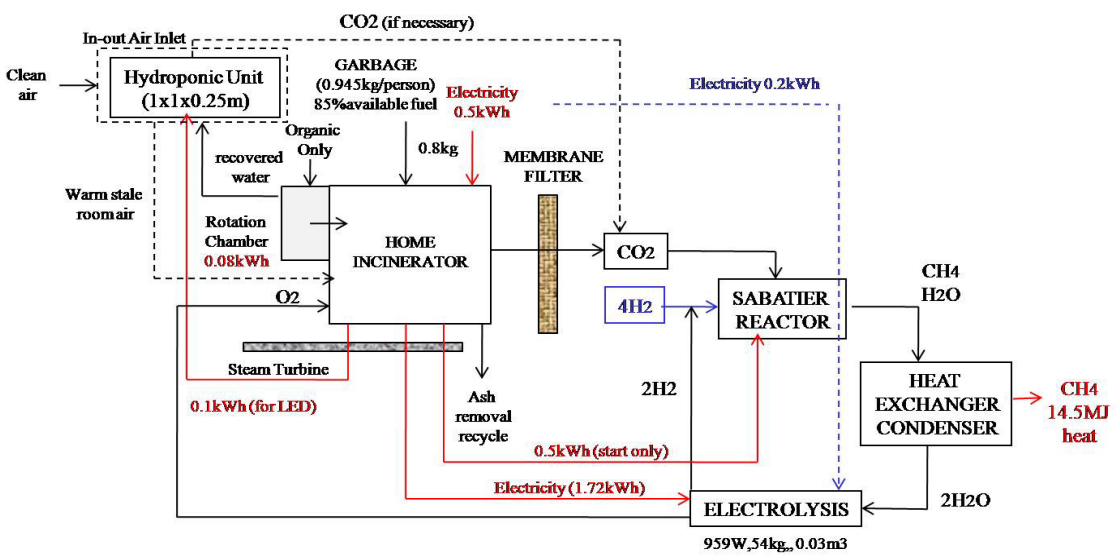

Figure 2: $\quad$ Semi-closed hydrogen-producing Sabatier system with electrolysis unit.

With regards to Fig.2, only $0.03 \mathrm{~m}^{3}$ additional volume $(54 \mathrm{~kg})$ is required to install the electrolysis unit, which produces half of necessary hydrogen, but a continuous energy source might be necessary as the total electricity produced would be used for electrolysis system.

\subsection{Closed hydrogen-loop home incineration system}

A closed-hydrogen loop would require processing both methane and water to break the hydrogen chains they inhabit with $100 \%$ system efficiency, where the process of methane starts with excess $\mathrm{CO}_{2}$ with a reactor as shown in eqn (3).

$$
\mathrm{CO}_{2}+\mathrm{CH}_{4}=2 \mathrm{H}_{2}+2 \mathrm{CO} \triangle \mathrm{H}=917-\mathrm{kj} / \mathrm{mol} \text { (endothermic) }
$$

Theoretically, this scenario of $262 \mathrm{~g}$ of excess methane with a thermal energy capacity of $8.34 \mathrm{MJ}$, produces $65 \mathrm{~g}$ hydrogen with a thermal energy of $8.56 \mathrm{MJ}$; a net gain of $3 \%$. But the reactor itself needs a heat source; although this could be achieved through a solar mirror array, the necessary thermal heat energy to run the reactor would be about $15 \mathrm{MJ}$, which would require $2.75 \mathrm{~m}^{2}$ of solar mirror area, considering solar intensity conditions in Japan.

At this point, the recovery of thermal heat from the incinerator surface might help to develop a compact system without additional thermal unit installation. 
The size of $0.6 \times 1 \times 1 \mathrm{~m}$ incinerator has four surfaces; each of $0.6 \mathrm{~m}^{2}$, with a total of $2.4 \mathrm{~m}^{2}$. As combustion occurs, outside air can be circulated to cool the incinerator and transfer heat through the reactor, and finally into the home regulated to necessary temperature. It would also control the access of outdoor pollutants while excess air would continue to run through the hydroponics unit, and then into the incinerator to make use of carbon content and build up common kitchen pollutants, such as formaldehyde and benzene creating an air-tight system, as shown in Fig.3.

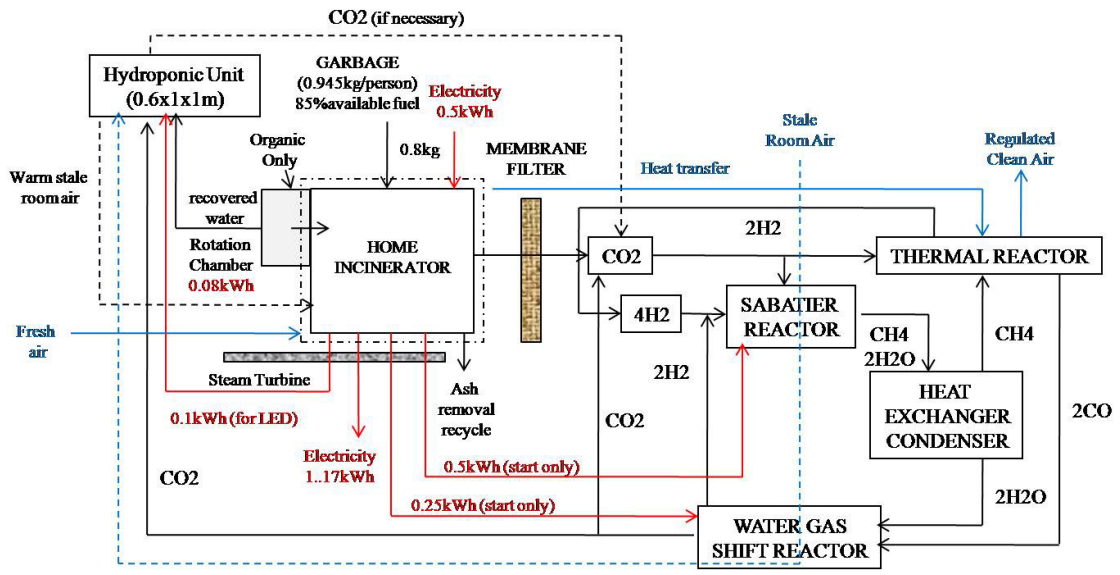

Figure 3: Closed Hydrogen-loop air-tight home incineration system.

While hydrogen is directed back to Sabatier reactor, the excess $\mathrm{CO}$ from eqn (3) would be fed into a water gas shift reactor with excess water, as shown in eqn (4).

$$
\mathrm{H}_{2} \mathrm{O}+\mathrm{CO}=\mathrm{H}_{2}+\mathrm{CO}_{2} \triangle \mathrm{H}=-40.6-\mathrm{kj} / \mathrm{mol} \text { (exothermic) }
$$

The reactor would be a stainless tubular unit, $1.2 \mathrm{~cm}$ in diameter and $30 \mathrm{~cm}$ in length. Yongtaek and Stenger state that exiting very low $\mathrm{CO}$ concentrations will require very low temperatures and/or high water to $\mathrm{CO}$ ratios, otherwise reducing output of $\mathrm{H}_{2}$ and $\mathrm{CO}_{2}$ to $70 \%$ [8]. If full capacity if achieved, this reaction will produce another $65 \mathrm{~g}$ of hydrogen and will completely close the reaction loop. Again, because the reaction is exothermic, cooling with stale room air or water could efficiently reduce heat losses. Eqn (4) will also produce $88 \mathrm{~g}$ $\mathrm{CO}_{2}$, where half of this amount will be fed to the reactor to continue the process; while the other half would be directed to the hydroponics unit so that it could be processed by plants to produce oxygen and food, or work as a backup system for Sabatier reactor in case if there is a necessity for additional $\mathrm{CO}_{2}$, which would not be recovered from the incinerator due to the amount or contents of garbage produced. Daily energy output would be $1.17 \mathrm{kWh}$. An additional $0.02 \mathrm{~m}^{3}$ storage space for $\mathrm{CO}_{2}$ could be located below the hydroponics unit. The total necessary volume will increase by $0.05 \mathrm{~m}^{3}$. 


\section{The decentralized kitchen}

We next describe the installation process and possible environmental impact.

\subsection{Installation of waste management unit}

All the home incineration scenarios with Sabatier reactor, either hydrogensupplied, semi- or totally closed require additional space to be installed inside the kitchen; from a minimum of $1.93 \mathrm{~m}^{3}$ to a maximum of $2.11 \mathrm{~m}^{3}$, including the volume requirement for hydroponics unit. The home incinerator and hydroponics unit are the most space consuming elements, each requiring $0.6 \mathrm{~m}^{3}$.

The incinerator can basically replace the space reserved for garbage boxes under the sink. Garbage can be fed through two openings (organic and others) next to the working area. The Sabatier unit is quite compact and can easily be installed behind the shelves enabling simple access and easy maintenance.

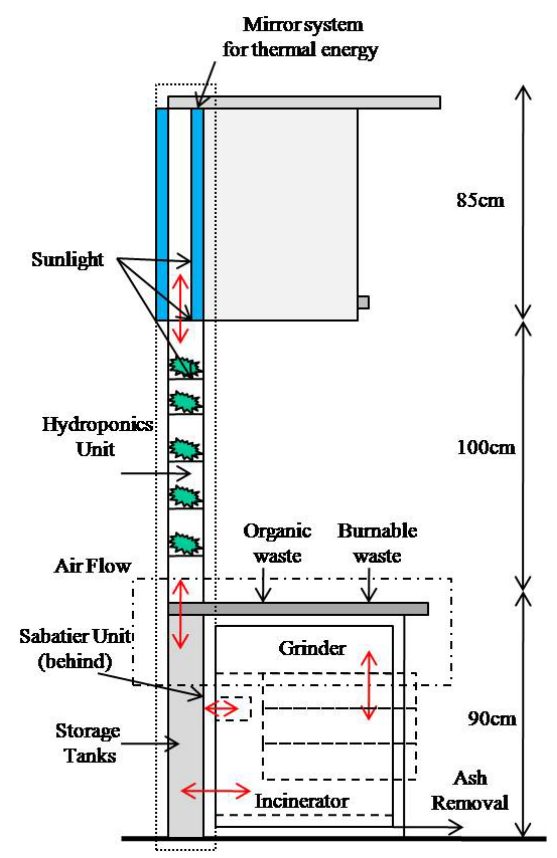

Figure 4: $\quad$ System sketch for prefab wall.

As shown in Fig.4, we propose a pre-fabricated wall to install the hydroponics unit located within the front wall, functioning both as a window and sub-system for waste management utility, and providing better insulation and improving plant growth conditions using stale room air. The current traditional assemblylines of Japanese housing companies could construct prefab wall-units with a thickness of $70 \mathrm{~cm}$, using current production technology. Thus, the prefabricated wall unit could provide $5 \mathrm{~m}^{3}$ space, not only for hydroponics unit, but also for the 
storage tanks of IF-Kitchen and a mirror system above for extra thermal power collection utilizing 'dead spaces' in our kitchens, which IF defines 'as areas that are located behind the working counter or overhead bins'.

\subsection{Environmental impact}

IF Kitchen would have a large impact in reducing $\mathrm{CO}_{2}$ emissions, which would have otherwise be released from the social and physical solid waste infrastructural system; collection, transport, treatment and disposal. Currently, the Japanese population is $127,785,000$ [9], where an average person produces $1.086 \mathrm{~kg} /$ day as garbage [10]; a total of 50.65 million tons/year. Incinerating counts for $77 \%$ of the total; emitting 39 million tons of $\mathrm{CO}_{2}$ in the atmosphere.

The ecological footprint of waste transportation could be calculated by assuming a $\mathrm{CO}_{2}$ emission factor for LPG of $289.3 \mathrm{~g} / \mathrm{km}$ (based on the factor of low carbon content- $1.6 \mathrm{~kg} / 1$ for $\mathrm{LPG}$ with $6 \mathrm{~km} / 1$ consumption) a total travel distance of $45 \mathrm{~km}$ (the distance each truck delivers garbage to the nearest facility), equivalent to $13.02 \mathrm{~kg} \mathrm{CO} \mathrm{CO}_{2} /$ vehicle/day. Average load per truck is 4 tonnes, emissions per tonne of collected waste can be calculated as in eqn (5):

$13.02 \div 4=3.255 \mathrm{~kg} \mathrm{CO}_{2}$ per tonne waste

$90 \%$ of the waste is collected by garbage trucks in Tokyo, which lasts in an emission of 148.37 million tons/year. Together with incineration process, it counts for 187.37 million tons greenhouse gas emission. Japan targets a reduction in greenhouse emission by 6 percent under the Kyoto Protocol, but changes in emissions from 1990 to 2004 showed an increase of $6.5 \%$ [11]. In Fiscal year 2006, Japan emitted 1341 million metric tons; lower than the previous year but still a 5.4\% increase from 1990 level. The decentralization process of $\mathrm{HH}$ with the IF-Kitchen could reduce $\mathrm{CO}_{2}$ emissions to 1153.63 million tonnes; a 9.06\% reduction from 1990 values; far below targeted levels.

\subsection{Further requirements}

Current technologies range between 50-85\% depending on source composition or technology level. This would gradually reduce the final amount of available $\mathrm{CO}_{2}$ and $\mathrm{H}_{2}$ to $50 \%$. The extra $\mathrm{CO}_{2}$ would be recovered from incineration process but an additional $\mathrm{H}_{2}$ supply would still be crucial. A $100 \%$ system efficiency would require an intensive research on hydroponics technology to reduce extra $\mathrm{CO}_{2}$. A tank could also be used to store $\mathrm{CO}_{2}$ to start the reaction.

Ash is removed from the incinerator and collected on the same day with cans and bottles, which were calculated as $10 \%$ of garbage as not collected by garbage trucks in section 4.2, without lasting in any additional emission. Further studies should be conducted for the reuse of such materials for buildings or roads.

IF Kitchen could create an enormous market for housing industry all over the world. Many companies might challenge the production of a better technology, which could improve the efficiency of system in short time. District offices could offer a tax exemption for kuminzei-a residential tax in Japan (about $\$ 300$ per $\mathrm{HH}$ ) collected for district services- mainly for garbage collection. 
For comparison, Matsushita Electric Industrial Co Ltd offers $\mathrm{HH}$ fuel cells for $\$ 10,000$ with a reformer using city gas (methane) for hydrogen production [12]. A doubled cost assumption of $\$ 20,000$ for IF-Kitchen can be subsidized in 6 years with $90 \%$ kuminzei exemption due to the amount of garbage reduced at each $\mathrm{HH}$. Thus, it would greatly reduce the stress on expensive landfill area.

\section{Conclusion}

An IF-Kitchen running a Sabatier reactor could provide energy and water in a $\mathrm{HH}$. Integration of a closed-hydrogen loop could further decentralize a $\mathrm{HH}$ by reducing stress on physical and social solid waste management infrastructure, decreasing greenhouse emissions and improving resource integration. Using a prefab wall unit could reduce the required installation area to less than $1 \mathrm{~m}^{3}$.

Further research will focus on integrations of different sub-system architectures and decentralization by integrating wastewater with solid waste management system in order to propose a completely self-sufficient IF-House.

\section{References}

[1] GE Consumer \& Industrial http://www.geconsumerproducts.com/ pressroom/

[2] Anilir S., Matsumura S., Schmidt R. et.al., Infra-Free Life (IFL)- Proposal for a spin-off technology from aerospace into building industry, AIAA Space 2006 Proceedings, 2006-7329

[3] Anilir S., Nelson M., Allen J.P., Designing a small-scale Infra-Free system for community applications: Managing Energy, Water and Waste, Journal of Asian Architecture and Building Engineering, Vol.7, No.1, May 2008

[4] Incinerator for Home Use, US Patent 6422159, Free Patents Online

[5] http://www.freepatentsonline.com/6422159.html

[6] Waste-to-Energy in Denmark, The most efficient waste management in Europe, Reno Sam and Ramboll, 2006

[7] VanderWiel D.P., Zilka-Marko J., Wang Y., Tonkovich A., Wegeng R., Carbon dioxide conversions in Micro reactors, AlChe 2000 Spring National Meeting, Atlanta, GA

[8] Watanabe K., Waste and Sustainable Consumption- Case Study: Neyagawa City, Capability and Sustainability Center, St. Edmund's College Cambridge, March 2005

[9] Yongtaek C., Stenger H.G., Water gas shift reaction kinetics and reactor modeling for fuel cell grade hydrogen, Science Direct, Journal of Power Sources, Volume 124, Issue 2, November 2003, pp. 432-439

[10] Japanese Statistics Bureau, Population estimates by Age and Sex, http://www.stat.go.jp/data/jinsui/tsuki/index.htm (Japanese)

[11] Ministry of Internal Affairs and Communications, Statistics Bureau \& Statistical Research and Training Ins., Statistical Handbook of Japan 2007, p. 167

[12] United Nations Framework Convention on Climate Change (UNFCCC), Changes in GHG emissions from 1990 to 2004 for Annex 1 Parties

[13] Matsushita Electric Co. Ltd. www.panasonic.co.jp/appliance/global/FC 